\title{
Atherosclerosis and Colorectal Carcinogenesis: Shared Risk Factors or Common Pathogenesis?
}

\author{
Mark Hull Prashant Kant \\ Leeds Institute of Molecular Medicine, St. James's University Hospital, Leeds, UK
}

In this issue of Digestion, Kim and colleagues demonstrate a significant association between the detection of carotid artery stenosis (defined here as greater than 50\% luminal narrowing) and the presence of one or more colorectal adenomas in nearly 1,900 middle-aged Korean men undergoing routine health screening who were not taking aspirin or a statin [1].

Carotid artery stenosis was more frequently detected in individuals harbouring a colorectal adenoma(s) compared with those without a colorectal neoplasm [1]. These data add to a growing literature that demonstrates a link between atherosclerotic disease and the presence of colorectal neoplasia [2]. One explanation is the existence of many shared risk factors for vascular disease and development of colorectal neoplasia such as tobacco smoking, obesity, metabolic syndrome and type II diabetes mellitus [3]. However, an alternative explanation, as pointed out by Kim et al. [1], is a possible shared pathogenic factor; chronic inflammation.

The inflammatory process is now understood to be central to atherosclerosis [4]. Less well-recognised is the role of inflammation in so-called 'sporadic' colorectal carcinogenesis, as opposed to colorectal neoplasia developing on a background of longstanding inflammatory bowel disease. Several strands of indirect evidence link 'sporadic' colorectal carcinogenesis and chronic inflammation including the association between raised C-reactive protein levels and incident colorectal cancer [5], the consistent protective effect of regular use of non-steroidal anti-inflammatory drugs [6] and the important role of several pro-inflammatory cytokines during carcinogenesis [7]. Interestingly, the cyclooxygenase- 2 enzyme, which is established as an effective chemoprevention target, is present predominantly in stromal cells, including macrophages, in 'sporadic' colorectal adenomas, reminiscent of a chronic inflammatory cell infiltrate [8].

Moreover, shared molecular mechanisms in atherosclerosis and colorectal carcinogenesis are now being uncovered. For example, the pro-inflammatory cytokine macrophage migration inhibitory factor (MIF) has been discovered to play a role during atherogenesis [9] and the early stages of colorectal carcinogenesis [10].

Further epidemiological studies of the relationship between atherosclerotic disease and colorectal neoplasia, particularly in non-Asian populations, and greater understanding of the role of chronic inflammation during atherosclerosis and colorectal carcinogenesis, as well as elucidation of the link with predisposing pro-inflammatory states such as obesity [11], should prompt evaluation of the role of inflammation biomarkers such as CRP and serum cytokine levels as predictors of future neoplastic risk in the colorectum in at-risk groups such as the obese. 'Anti-inflammatory' therapy in its broadest sense (of which aspirin can be thought of as an example) is an attractive strategy which could combine cancer prevention and vascular prophylaxis.

\section{KARGER}

Fax +4161306 1234 E-Mail karger@karger.ch www.karger.com
(C) 2009 S. Karger AG, Base

0012-2823/10/0811-0016\$26.00/0

Accessible online at:

www.karger.com/dig
Mark Hull

St. James's University Hospital, Molecular Gastroenterology

Leeds Institute of Molecular Medicine, Wellcome Trust Brenner Building Leeds LS9 7TF (UK)

Tel. +44113343 8650, Fax +44113343 8702, E-Mail m.a.hull@leeds.ac.uk 


\section{References}

1 Kim BJ, Kim JY, Chang DK, Son HJ, Rhee PL, Kim JJ, Rhee JC, Choe YH, Choi YH, Shim SG, Kim YH: Co-existence between carotid artery stenosis and colorectal adenomatous polyps in middle-aged men. Digestion 2010; $81: 20-26$

2 Chan AOO, Jim MH, Lam KF, et al: Prevalence of colorectal neoplasm among patients with newly diagnosed coronary artery disease. JAMA 2007;298:1412-1419.

-3 Kahi CJ, Rex DK, Imperiale TF: Screening, surveillance, and primary prevention for colorectal cancer: a review of the recent literature. Gastroenterology 2008; 135:380399.
4 Libby P: Inflammation in atherosclerosis. Nature 2002;420:868-874.

5 Tsilidis KK, Branchini C, Guallar E, Helzlsouer KJ, Erlinger TP, Platz EA: C-reactive protein and colorectal cancer risk: a systematic review of prospective studies. Int J Cancer 2008; 123:1133-1140.

- 6 Arber N, Levin B: Chemoprevention of colorectal neoplasia: the potential for personalized medicine. Gastroenterology 2008; 134:1224-1237.

7 Robinson SC, Coussens LM: Soluble mediators of inflammation during tumor development. Adv Cancer Res 2005;93:159-187.

8 Chapple KS, Cartwright EJ, Hawcroft G, et al: Localisation of cyclooxygenase-2 in human sporadic colorectal adenomas. Am J Pathol 2000;156:545-553.
9 Morand EF, Leech M, Bernhagen J: MIF: a new cytokine link between rheumatoid arthritis and atherosclerosis. Nat Rev Drug Discov 2006;5:399-411.

10 Wilson JM, Coletta PL, Cuthbert RJ, et al: Macrophage migration inhibitory factor promotes intestinal tumorigenesis. Gastroenterology 2005;129:1485-1503.

11 Giovannucci E, Michaud D: The role of obesity and related metabolic disturbances in cancers of the colon, prostate, and pancreas. Gastroenterology 2007;132:2208-2225. 